CLINICAL STUDY

\title{
Identification of a clinically homogenous subgroup of benign cortisol-secreting adrenocortical tumors characterized by alterations of the protein kinase A (PKA) subunits and high PKA activity
}

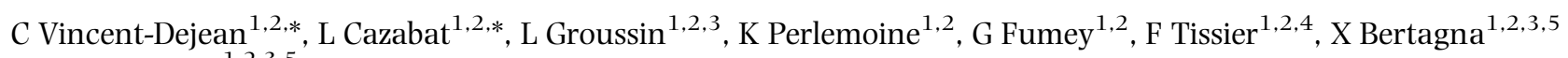 \\ and J Bertherat ${ }^{1,2,3,5}$ \\ ${ }^{1}$ INSERM U567, CNRS UMR8104, Endocrinology, Metabolism and Cancer Department, Institut Cochin, 75014 Paris, France, ${ }^{2}$ Université Paris \\ Descartes, 75014 Paris, France, ${ }^{3}$ Assistance Publique Hôpitaux de Paris, Department of Endocrinology, Center for Rare Adrenal Diseases, Hôpital Cochin, \\ Paris, France, ${ }^{4}$ Assistance Publique Hôpitaux de Paris, Department of Pathology, Hôpital Cochin, Paris, France and ${ }^{5}$ COMETE-INCA-Rare Adrenal Cancer \\ Network, 75014 Paris, France \\ (Correspondence should be addressed to J Bertherat who is now at Service des Maladies Endocriniennes et Métaboliques, Hôpital Cochin, 27 rue du Faubourg \\ Saint-Jacques, 75014 Paris, France; Email: jerome.bertherat@cch.aphp.fr)
}

${ }^{*} \mathrm{C}$ Vincent-Dejean and L Cazabat contributed equally to this work

\begin{abstract}
Objective: The cAMP/protein kinase A (PKA) pathway plays an important role in endocrine tumorigenesis. PKA is a heterotetramer with two regulatory subunits (four genes: PRKAR1A, PRKAR1B, PRKAR2A, PRKAR2B) and two catalytic subunits. Inactivating PRKAR1A mutations have been observed in Carney complex and a subset of adrenocortical tumors (ACT). This study was designed to search for other alterations of PKA in ACT, and to establish their correlation with the clinical characteristics.

Methods: In this study, 35 ACT (10 non-secreting adrenocortical adenomas (ACA-NS), 13 cortisolsecreting adenomas (ACA-S), and 12 malignant s (ACC)) were studied. PKA subunits were studied by western blot and RT-qPCR. The PKA activity was measured.

Results: A subgroup of ACA-S with a 96\% R2B protein decrease by comparison with normal adrenal $(4.1 \% \pm 4$ vs $100 \% \pm 19, P<0.001)$ was identified, ACA-S2 $(6 / 13)$. By contrast, no differences were observed in ACC and ACA-NS. The level of R1A mRNA was decreased in ACA-S $(P<0.001)$, but not the level of R2B mRNA. No mutation of the R2B gene was detected in ACA-S2. The ACA-S2 group with loss of R2B protein showed a threefold higher basal PKA activity than the ACA with normal R2B protein $(3.37 \pm 0.31$ vs $1.00 \pm 0.20, P<0.0001)$. The ACA-S2 tumors with the loss of the R2B protein presented a homogenous phenotype and were all small benign cortisol-secreting tumors.

Conclusion: This loss of PRKAR2B protein due to a post-transcriptional mechanism in ACA-S is a new mechanism of cAMP pathway dysregulation in adrenocortical tumorigenesis. It defines a new subtype of secreting adenomas with high basal PKA activity presenting a homogenous clinical phenotype.
\end{abstract}

European Journal of Endocrinology 158 829-839

\section{Introduction}

Sporadic unilateral adrenocortical tumors (ACT) can be classified as benign adrenocortical adenomas (ACA) and malignant adrenocortical cancers (ACC). The symptoms due to ACA can be caused by steroid excess in the case of secreting adenomas (ACA-S), but most ACA are nonsecreting (ACA-NS). On the other hand, the consequences of ACC can be due to both steroid oversecretion and tumor growth or metastasis. Most ACA-S are small welldifferentiated tumors with a low tumor growth potential. Although various molecular alterations have been reported in ACT (1), the molecular and cellular mechanisms leading to these very different clinical phenotype and tumor growth potentials are poorly understood.

The cAMP/protein kinase A (PKA) pathway plays an important role in endocrine tumorigenesis $(2,3)$. Various components of this pathway have been implicated in adrenocortical tumorigenesis, including the adrenocorticotropin (ACTH) receptor, the Gas subunit of Gs protein, the PKA regulatory subunit type 1 A (PRKAR1A), and more recently the phosphodiesterase PDE11A (4-9). The PRKAR1A gene was found to be responsible for most cases of primary pigmented adrenocortical disease (PPNAD), a rare cause of ACTHindependent Cushing syndrome (10, 11). Germline PRKAR1A-inactivating mutations were found in both 
patients with isolated PPNAD (5) and those with Carney complex $(\mathrm{CNC})(11)$, a multiple neoplasia syndrome with PPNAD as its main endocrine manifestation (12). We have also observed somatic PRKAR1A mutations and $\mathrm{R} 1 \mathrm{~A}$ down-regulation in a subset of sporadic-secreting ACA (13).

PKA is a heterotetramer consisting of two regulatory and two catalytic subunits. Two major isoenzymes, termed PKA type I and II, have been identified based on their patterns of chromatographic elution (14). The characteristics of type I and type II PKA depend mainly on the structure and proprieties of the regulatory subunits. Four regulatory subunit (R) isoforms (R1a, $\mathrm{R} 1 \mathrm{~b}, \mathrm{R} 2 \mathrm{a}$, and R2b) and three isoforms for the catalytic subunit $(\mathrm{C} \alpha, \mathrm{C} \beta$, and $\mathrm{C} \gamma)$ have been identified in humans. The type I PKA contains either regulatory subunit $\mathrm{R} 1 \mathrm{a}$ or $\mathrm{R} 1 \mathrm{~b}$ and the type II PKA contains either regulatory subunit R2a or R2b. The four types of regulatory subunits have different expression patterns in mammals. The expression of PRKAR1A and PRKAR2A is almost ubiquitous. PRKAR1B is expressed in the brain, testis, and lymphocytes. PRKAR $2 B$ is expressed in the brain, adipose tissue, and in some endocrine tissues $(15,16)$. In vitro studies suggest distinct properties between type I and type II PKA; type I would be related to cell proliferation, whereas type II would be involved in tissue differentiation. However, in vivo studies are not so clear-cut and some observations suggest the possibility of a compensatory regulation between type I and type II (17). This tight regulation between type I and type II PKA rises up the possibility that subunits of PKA other than PRKAR1A could be altered in endocrine tumorigenesis.

The aim of this study was to search for alterations of the various subunits of PKA in ACT which do not have a somatic PRKAR1A mutation and their consequences on PKA activity. Dramatic alterations of PRKAR2B were observed in a subset of ACA that present homogenous alterations of PKA activity and subunit expression. These PKA alterations are associated with a homogenous tumor phenotype responsible for Cushing syndrome and presenting a very low growth potential.

\section{Materials and methods}

\section{Patients and tumor collection}

Thirty-five patients (29 women and 6 men, aged 15-77 years, see Tables 1 and 2) with ACT were included in this

Table 1 Clinical characteristics of patients with adrenocortical adenomas (ACA): 10 non-functioning adenomas (ACA-NS) and 13 cortisolsecreting adenomas (ACA-S).

\begin{tabular}{|c|c|c|c|c|c|c|c|}
\hline Group & Patients & Sex & Age (years) & UFC ( $\mu \mathrm{g} /$ day) & ACTH $(\mathrm{pg} / \mathrm{ml})$ & Tumor weight (g) & Dimensions $(\mathrm{cm})$ \\
\hline \multirow[t]{10}{*}{ ACA-NS } & $\mathrm{A} 1$ & $\mathrm{~F}$ & 26 & 29 & 12 & 10 & $1 \times 2$ \\
\hline & $\mathrm{A} 2$ & $\mathrm{~F}$ & 38 & 10 & 8 & 16 & $3 \times 3 \times 2.5$ \\
\hline & A3 & $\mathrm{F}$ & 48 & 66 & NA & 25 & $3 \times 3 \times 2.5$ \\
\hline & A4 & $\mathrm{F}$ & 62 & $\mathrm{~N}$ & $\mathrm{~N}$ & 16 & $4 \times 3 \times 3$ \\
\hline & A5 & $\mathrm{F}$ & 68 & $\mathrm{~N}$ & NA & 22 & $4 \times 2.5 \times 4$ \\
\hline & A6 & M & 41 & 46 & NA & 31 & $5 \times 4 \times 3.5$ \\
\hline & A7 & M & 68 & $\mathrm{~N}$ & NA & 30 & $5 \times 3.5 \times 5$ \\
\hline & A8 & $\mathrm{F}$ & 71 & $\mathrm{~N}$ & NA & 32.5 & $5 \times 5 \times 3$ \\
\hline & A9 & M & 57 & 53 & 6 & 24.4 & $3.5 \times 3 \times 3$ \\
\hline & A10 & $\mathrm{F}$ & 70 & $\mathrm{~N}$ & NA & $82^{*}$ & $3 \times 2$ \\
\hline \multirow{8}{*}{$\begin{array}{l}\text { ACA-NS } \\
\text { ACA-S1 }\end{array}$} & & $7 F / 3 M$ & $54.9 \pm 5$ & $41 \pm 10$ & $8.7 \pm 1.7$ & $28.9 \pm 6.3$ & \\
\hline & A11 & $\mathrm{F}$ & 32 & 190 & $<2$ & 16 & 3 \\
\hline & A12 & $\mathrm{F}$ & 37 & 101 & $<2$ & 8 & $2.5 \times 2$ \\
\hline & $\mathrm{A} 13$ & $\mathrm{~F}$ & 51 & 68 & 1.5 & 46 & $5.8 \times 4.8 \times 4.3$ \\
\hline & A14 & $\mathrm{F}$ & 41 & 490 & L & 8 & 3 \\
\hline & A15 & $\mathrm{F}$ & 70 & 176 & $<2$ & 25.2 & $4 \times 3 \times 4$ \\
\hline & A16 & $\mathrm{F}$ & 48 & 1142 & $<2$ & 17 & $4 \times 3.5 \times 3$ \\
\hline & A17 & $\mathrm{F}$ & 50 & 140 & $<2$ & 45 & $5.5 \times 4 \times 5$ \\
\hline ACA-S1 & & $7 F$ & $47 \pm 4.7$ & $330 \pm 145$ & $<2$ & $23.6 \pm 6.1$ & \\
\hline \multirow[t]{6}{*}{ ACA-S2 } & A18 & $\mathrm{F}$ & 57 & $\mathrm{H}-\cdot-{ }_{0}$ & L & 14 & $3 \times 2.5 \times 2$ \\
\hline & A19 & $\mathrm{F}$ & 42 & 84 & 6 & 14 & $3 \times 2.3 \times 3$ \\
\hline & A20 & $\mathrm{F}$ & 38 & 319 & $<5$ & 22 & $4 \times 3.5 \times 2.5$ \\
\hline & A21 & $\mathrm{F}$ & 37 & 961 & 7 & 12.7 & 4 \\
\hline & A22 & $\mathrm{F}$ & 55 & 1250 & 8 & 10 & $3.5 \times 2.5 \times 3$ \\
\hline & A23 & $\mathrm{F}$ & 44 & 213 & 2 & 11.5 & $3 \times 2.5 \times 2.5$ \\
\hline $\begin{array}{l}\text { ACA-S2 } \\
\text { ACA-S }\end{array}$ & & $\begin{array}{l}6 F \\
13 F\end{array}$ & $\begin{array}{l}45.5 \pm 3.5 \\
46.3 \pm 2.9\end{array}$ & $\begin{array}{l}565 \pm 228 \\
428 \pm 126\end{array}$ & $\begin{array}{l}5.6 \pm 1 \\
3.8 \pm 0.7\end{array}$ & $\begin{array}{l}14 \pm 1.7 \\
19.2 \pm 3.5\end{array}$ & \\
\hline All ACA & & $20 \mathrm{~F} / 3 \mathrm{M}$ & $50 \pm \overline{2} .8$ & $330 \pm 103$ & $4.9 \pm 0.9$ & $23.4 \pm 3.5$ & \\
\hline
\end{tabular}

The ACA-S group is divided in the table between the ACA-S1 and ACA-S2 according to their R2B protein status (ACA-S2 group presenting a decrease in the $\mathrm{R} 2 \mathrm{~B}$ protein as determined by western blot analysis in the results). The age represents the age at surgery. $\mathrm{F}$, female, $\mathrm{M}$, male. The weight and dimensions of the tumor were determined by the pathologist ( ${ }^{*}$ the $82 \mathrm{~g}$ tumor was associated with a hematoma and the weight represents the tumor associated with the hematoma). Hormonal investigations performed in the same laboratory (Cochin Hospital are given) are given and the normal range are for urinary free cortisol (UFC) $<90 \mu \mathrm{g} /$ day and for adrenocorticotropin (ACTH) $20-60 \mathrm{pg} / \mathrm{ml}$. For the hormonal investigations not performed in the central laboratory interpretation of the results are only given ( $\mathrm{N}$, normal, $\mathrm{L}$, low, and $\mathrm{H}$, high, by comparison with normal values of the local laboratory). For each group, the lower lines give the sex repartition or the mean \pm S.E.M. 
Table 2 Clinical characteristics of patients with adrenocortical carcinomas.

\begin{tabular}{|c|c|c|c|c|c|}
\hline Patients & Sex & Age (years) & Tumor weight (g) & Weiss score & Secretion \\
\hline C1 & $\mathrm{F}$ & 15 & 22 & 3 & $\mathrm{GC}+\mathrm{A}$ \\
\hline $\mathrm{C} 2$ & $\mathrm{~F}$ & 51 & 114 & 5 & $\mathrm{GC}+\mathrm{A}$ \\
\hline C3 & M & 73 & 620 & 8 & $\mathrm{GC}$ \\
\hline C4 & $\mathrm{F}$ & 77 & 2700 & 8 & $\mathrm{GC}+\mathrm{A}+\mathrm{MC}$ \\
\hline C5 & $\mathrm{F}$ & 53 & 104 & 4 & $\mathrm{GC}+\mathrm{A}+\mathrm{MC}$ \\
\hline $\mathrm{C} 6$ & $\mathrm{M}$ & 52 & 827 & 8 & $\mathrm{GC}+\mathrm{A}+$ Precursor \\
\hline $\mathrm{C7}$ & M & 63 & 135 & 8 & $\mathrm{GC}+\mathrm{E}_{2}+\mathrm{MC}$ \\
\hline $\mathrm{C} 8$ & $\mathrm{~F}$ & 27 & 570 & 7 & A \\
\hline C9 & $\mathrm{F}$ & 65 & 45 & 3 & $\mathrm{GC}$ \\
\hline C10 & $\mathrm{F}$ & 26 & 50 & 3 & $\mathrm{GC}+\mathrm{A}+\mathrm{E}_{2}$ \\
\hline C11 & $\mathrm{F}$ & 31 & 40.0 & 4 & $\mathrm{GC}+\mathrm{A}$ \\
\hline C12 & $\mathrm{F}$ & 26 & 61 & 3 & $\mathrm{GC}+\mathrm{A}$ \\
\hline ACC & $9 \mathrm{~F} / 3 \mathrm{M}$ & $46.6 \pm 6$ & $441 \pm 220$ & $5.7 \pm 0.7$ & \\
\hline
\end{tabular}

The table summarizes the main clinical characteristics of the 12 patients with adrenocortical carcinomas. The age represents the age at surgery. $F$, female, $M$, male. The weight of the tumor is determined by the pathologist and the Weiss score analyzed by the same pathologist. The steroid oversecretion is given as follows: GC, glucocorticoids; $A$, androgens; MC, mineralocorticoids; $E_{2}$, estradiol. The lower line gives the sex repartition and mean \pm s.E.M.

study. Here, 10 patients presented with non-functioning ACA (ACA-NS), 13 with cortisol-secreting adenomas without R1A mutation (ACA-S), and 12 with ACC. The hormonal investigations were performed as previously reported $(5,6)$. To detect the cortisol-secreting tumors at least three of the following hormonal investigations were performed: urinary free cortisol, plasma ACTH, midnight plasma or salivary cortisol, and cortisol response to overnight or low-dose dexamethasone test. An ACA was classified as ACA-NS when the clinical signs of Cushing syndrome were lacking, or moderate and non-specific, and when the cortisol investigations were in the normal range. When the clinical signs of Cushing's syndrome were present and when at least three of the biological parameters were clearly abnormal, an ACA was classified as secreting (ACA-S).

Adrenocortical tissues dissected from six normal adrenals (NA) collected during surgery for tumor of the kidney or juxta-adrenal tumors presenting like nonsecreting incidentaloma were also studied.

Tumor and tissue fragments obtained during surgery were immediately dissected by the pathologist, frozen, and stored in liquid nitrogen until use. The tumor weight and size were determined by the pathologist after periadrenal fat removal. For diagnosis and scoring, the tumors were fixed in formalin, embedded in paraffin, and $4 \mu \mathrm{m}$ sections were cut and stained with hematoxylin and eosin. Pathological data were assessed according to Weiss criteria. All ACA had a Weiss score $<2$. Informed signed consent for tumor analysis and for access to the data collected was obtained from all the patients, and the study was approved by an Institutional Review Board (Comité Consultatif de Protection des Personnes dans la Recherche Biomédicale, Cochin Hospital, Paris).

\section{Western blot analysis}

Western blot analysis of regulatory R1A, R2A, and R2B subunits and $\mathrm{C} \alpha$ catalytic subunit were done in all ACT samples with monoclonal antibodies specific for R1A, R2A, R2B, and C $\alpha$ from BD Transduction Laboratories (Lexington, KY, USA) at dilutions specified by the manufacturer, as described previously $(11,18)$. After exposure, the films were scanned, and the signals were digitized by the GeneTools ${ }^{\circledR} 1.0$ analysis system.

\section{Immunohistochemistry}

Four micron sections from formalin-fixed tissue embedded in paraffin were mounted on Superfrost/Plus glass slides. The paraffin was eliminated by incubating the sections in xylene followed by rehydration. The slides were incubated with monoclonal antibodies specific for R2B (BD Transduction Laboratories, San Diego, CA, USA) at a dilution of 1:500 for $30 \mathrm{~min}$ at room temperature. The sections were then incubated with the streptavidinbiotin-peroxidase complex and the marker was detected by the enzymatic precipitation of 3.3'-diaminobenzidine tetrahydrochloride in $0.5 \mathrm{mmol}$ Tris. The slides were counterstained with Mayer hematoxylin.

\section{Sequencing analysis of the PRKAR2B gene}

The 11 exons and flanking intronic sequences of the PRKAR2B gene were separately PCR amplified using the following primers: exon 1, 5'-CTC AGC CGC CGC CAC CAC AC 3'-GGC AAG ATC CGA GAG CAC AGC; exon 2, 5'-TAT TTC CTC TTA TTT ATT CAT 3'-TTC TTT GTA CCT TCT TGT CC; exon 3, 5'-ATT GTA GTA TGG TTT TTG ATG 3'-TCT TTT CTA TGA TTA TTT TCC; exon 4, 5'-CTT TGA GTG AGA TGG TAT TGG C 3 '-GGC AAA ACT CAA GAC CCT GTA; exon 5, 5'-CAT TTC TTT GGA CTT GTT CAC 3'-GTT GCC GTA ATA ATG GTT GAG; exon 6, 5'-TTA TTT CAG AGG GCT CTT TTC 3'-ATT TGT AAC ACC GTC ATA GCA; exon 7, 5'-TCT TGT AGG GAA TAA AAT AAA AC 3'-TAA AGC AAA ATA AAA TAA AAG CA; exon 8, 
5'-TAT GGG CTA TGT GAT GCT GA 3'-AGA TCT ACC ACT ACA GGA ACC; exons 9-10, 5'-ATT TGC ATT TTC ACC GTC TGT 3'-CAA AAC CTG TGA ACC CAA TAA; exon 11, 5'-ATC ATA TTG CCG AGG GAC TGC 3'-TCA CTA CAG GTC TTG CTC CAT AC. The amplified products were directly sequenced on an automated sequencer (ABI 3700; Perkin-Elmer Corp., Wellesley, MA, USA) using the Big Dye Terminator method.

\section{Quantitative RT-PCR}

Real-time PCR was performed using the Light Cycler apparatus (Roche Diagnostics $\mathrm{GmbH}$ ). For mRNA PRKAR1A and PRKAR2B analysis, cDNA was available for four non-secreting adrenal adenomas and nine cortisolsecreting adenomas. PCRs were performed in a $20 \mu \mathrm{l}$ final volume, $0.5 \mu \mathrm{M}$ oligonucleotide, $3.5 \mathrm{mM} \mathrm{MgCl}_{2}$, and the Fast Start DNA master SYBR Green (Roche) according to the manufacturer's recommendations. Glyceraldehyde 3-phosphate dehydrogenase (GAPDH) mRNA was amplified as the internal control. The primers used were as follows. For PRKAR1A: sense, 5'-AAT GGC CGC TTT AGC CAA AGC C and antisense, 5'-TTC TCC AAA GCT CCC TCC TTC; for PRKAR2B: sense, 5'-GGT GTT GGA AGA TGT GTT GGT A and antisense, $5^{\prime}$-CTT TTT GTT ACG GTT TTT CTC T, and for GAPDH amplification sense, 5'-GCC ACA TCG CTC AGA CAC CA and antisense, 5'-TTC CCG TTC TCA GCC TTG AC. Annealing was performed at $56^{\circ} \mathrm{C}$ for PRKAR1A amplification, $58^{\circ} \mathrm{C}$ for PRKAR2B, and $60^{\circ} \mathrm{C}$ for GAPDH. Product specificity was controlled by melting curve analysis and migration on a $1 \%$ agarose gel. All the reactions were performed in duplicate. Results were analyzed with the software of the Light Cycler apparatus (Roche Diagnostics $\mathrm{GmbH}$ ). Standard curve is determined by the use of a plasmid containing the PCR productamplified form cDNA made from RNA extracted from the H293 cell line and cloned in pGEM-T Easy, as reported previously (13).

\section{PKA activity}

PKA activity was measured in tumor samples using Peptag ${ }^{\circledR}$ non-radioactive cAMP-dependent protein kinase assay (V5340; Promega). All the samples were treated together, in duplicates. All samples were deposed in the same electrophoretic gel and the density under u.v. light was simultaneously measured using the Genetools 1.0 software (SYNGENE, Frederick, Maryland, USA). The basal PKA activity represents the difference between the ratio of the phosphorylated and the non-phosphorylated forms, without PKA inhibitor (PKI) and with PKI (40 ng/ $\mu \mathrm{l}$, Promega). The total PKA activity is the difference between the ratio of the phosphorylated and the non-phosphorylated forms after stimulation with $1 \mu \mathrm{M}$ cAMP, without PKI, and with PKI. The kinase activity in the presence of PKI is extremely low $(<5 \%)$ confirming the high specificity of the activity assayed.

\section{Statistical analysis}

The results are expressed as the mean \pm s.e.M. Comparisons between groups were done using unpaired $t$-test (Statview software version 5.0, SAS Institute, Cary. North Carolina, USA) and $P<0.05$ was accepted as statistically significant.

\section{Results}

\section{Clinical characteristics}

The patients with benign ACA were 20 females and 3 males, with a mean age of $50 \pm 2.8$ years (range 26-71) and a mean tumor weight $23.4 \pm 3.5 \mathrm{~g}$. Thirteen presented with a cortisol-secreting ACA (ACA-S) and all of them were females. The age at surgery and tumor weight were not significantly different in the ACA-S group and the non-secreting ACA (ACA-NS) group; the mean age was $46.3 \pm 2.9$ and $54.9 \pm 5$ years respectively $(P=0.32)$ and the tumor weight was $19.2 \pm 3.5$ (range 8-25.2) and 28.9 \pm 6.3 (range 10-82) respectively. Patients with an adrenocortical carcinoma (ACC) were nine females and three males, with an age (46.3 \pm 6.2 years) not different from the patients with an ACA. As expected, the tumor weight of ACC was higher than that of ACA $(520 \pm 236 \mathrm{~g}$ vs $23.4 \pm 3.5 \mathrm{~g}, P<0.01)$.

\section{Western blot studies}

The evaluation of the relative expression of different PKA regulatory subunits was done by western blotting in 23 adrenal adenomas and 12 adrenal carcinomas (Fig. 1A). A value of $100 \%$ has been arbitrarily given to the mean value of the NA. Western blotting with a R2B-specific antibody showed a considerable heterogeneity of R2B protein expression levels within the group of cortisolsecreting adenomas. This striking difference in R2B level led to the identification of a specific ACA-S subgroup that was virtually devoid of R2B protein termed ACA-S2 (6/13, ratio $\mathrm{R} 2 \mathrm{~B} /$ actin $<0.2$ ). Western blot analysis quantification showed a $96 \%$ decrease of R2B protein in the ACAS2 group compared with that of NA $(4.1 \% \pm 3$ vs $100 \% \pm$ 19 in NA $(P<0.001))$. By contrast, in the other ACA-S, termed ACA-S1, the R2B levels were not decreased in comparison with NA $(215 \% \pm 40$ vs $100 \% \pm 19$ in NA). The R2B level in the ACA-S2 group was also significantly lower than those in the other groups of tumors $(136 \% \pm$ 26 in ACA-NS $(P<0.01), 123 \% \pm 20$ in ACC $(P<0.001))$. A significant $\mathrm{R} 2 \mathrm{~A}$ protein decrease was also noted in the ACA-S2 group $(7 \% \pm 2)$ compared with NA $(100 \% \pm 25, P<0.05)$ but also with ACA-S1 $(63 \% \pm$ $19, P<0.05)$ and ACC $(57 \% \pm 9, P=0.001)$. The level of R1A in ACA-S2 was not different from that in NA $(51 \% \pm$ 11 vs $100 \% \pm 34, P>0.05)$ but was significantly lower than that in ACA-S1 $(169 \% \pm 35, P<0.05)$ and ACA-NS $(102 \% \pm 10, P<0.01)$. The level of $C \alpha$ was not significantly different in ACA-S2 when compared with that in 
A

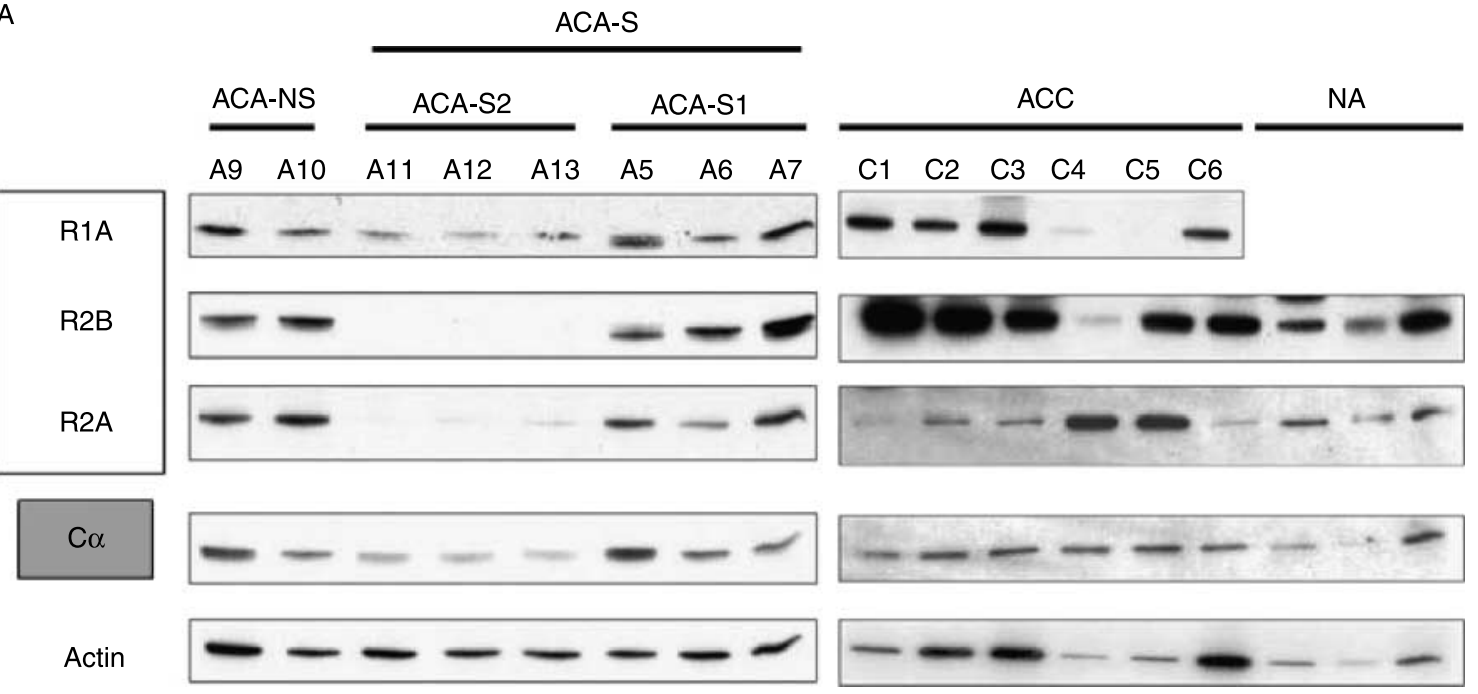

B

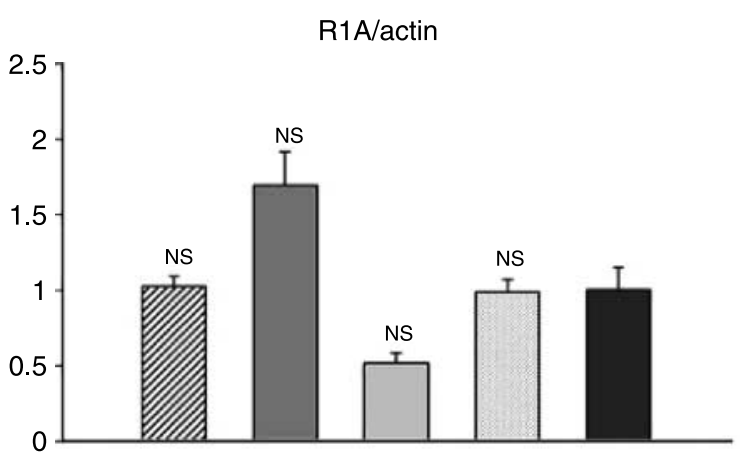

$\because \mathrm{ACA}-\mathrm{NS} \square \mathrm{ACA}-\mathrm{S} 1 \square \mathrm{ACA}-\mathrm{S} 2 \square \mathrm{ACC}$ aNA

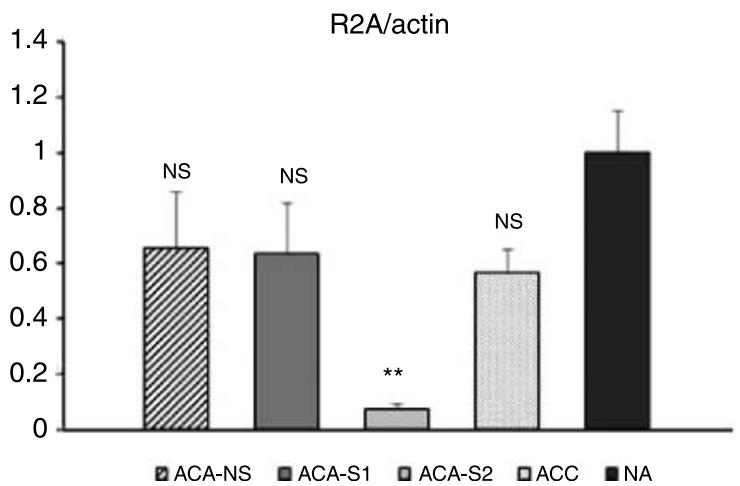

R2B/actin

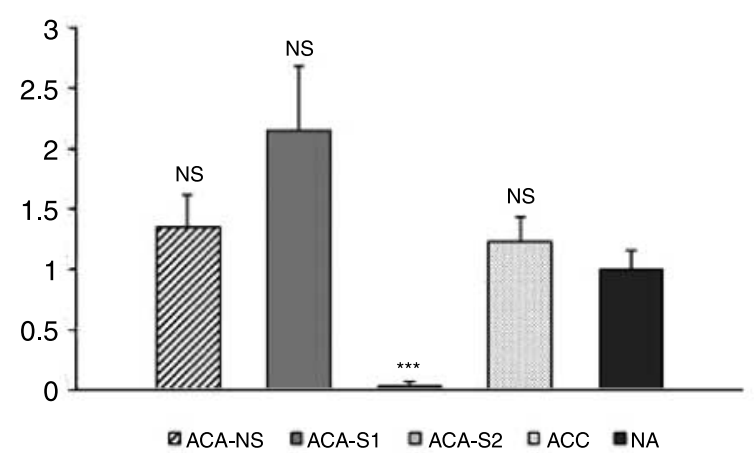

C $\alpha /$ actin

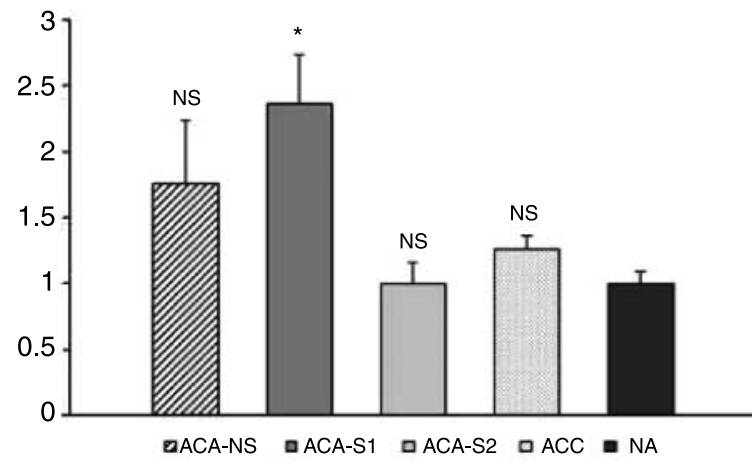

Figure 1 Western blotting of R1A, R2A, R2B, and $\mathrm{C} \alpha$ in sporadic adrenocortical tumors. Five milligrams of total cellular proteins were prepared from sporadic adrenocortical tumors: 10 non-functioning adenomas (ACA-NS), 13 cortisol-secreting adenomas (ACA-S), 12 adrenocortical carcinomas (ACC), and 6 normal adrenals (NA). A decrease in R2B protein is observed in half of the ACA-S. This subgroup is designated as ACA-S2. (A) Autoradiogram of Western blotting of R1A, R2A, R2B, C $\alpha$, and actin in representative tumors. (B) Quantification of Western blot. The PKA subunits/actin ratio is given in arbitrary absorbance units, with a value of 1 being given to the normal adrenal group (NA). The significance of the comparison between each group of tumors and normal adrenal (NA) is given. NS, not significant, $P>0.05 ;{ }^{\star} P<0.05 ;{ }^{\star \star} P<0.01 ;{ }^{\star \star \star} P<0.001$. 
NA $(100 \% \pm 16$ vs $100 \% \pm 18, P>0.05)$. However, interestingly, the level of $\mathrm{C} \alpha$ was higher in ACA-S1 $(237 \% \pm 38)$ than in the other groups of tumors $(100 \% \pm$ 16 in ACA-S2 $(P<0.01), 126 \% \pm 10$ in ACC $(P<0.01))$ and in NA $(100 \% \pm 18(P=0.01)$; Fig. $1 \mathrm{~B})$.

On the whole, it is important to note that the differences between NA and ACT were observed only for secreting adenomas. R2B and R2A are lower in ACA-S2 while Ca was higher in ACA-S1. This should lead to PKA dysregulation and increased enzymatic activity. No significant differences in the levels of the various PKA subunits could be detected between the NAs and ACC or ACA-NS (Fig. 1).

Interestingly, a positive correlation between the several regulatory subunits of PKA was observed in adrenal adenomas (data not shown), suggesting the existence of a coordinate fine tuning of their expression in ACA. In particular, a very significant correlation was noted between R2B and R2A proteins $(r=0.82, P<0.0001)$. On the contrary, there was no correlation between regulatory subunits in adrenal carcinomas, suggesting that the balance and the regulation of the expression of the PKA subunits in these cancers is regulated by clearly different mechanisms than those in adenomas.

\section{Immunohistochemistry}

Immunohistochemistry studies confirmed the dramatic reduction of R2B protein in the ACA-S2 subgroup of cortisol-secreting adenomas (Fig. 2). The adenomas from the ACA-S2 group were devoid of immunoreactivity with the R2B-specific antibody. On the contrary, the adenomas without $\mathrm{R} 2 \mathrm{~B}$ reduction by western blot (ACA-S1) and the non-functioning adenoma (ACANS) studied showed a strong cytoplasmic immunopositivity in more than $10 \%$ of the cells.

\section{PRKAR2B sequencing analysis}

In order to understand the molecular mechanisms of the $\mathrm{R} 2 \mathrm{~B}$ decrease in ACA-S2, we first searched for PRKAR2B somatic mutation in tumoral DNA extracted from the 5/6 available cortisol-secreting adenomas from the ACA-S2 group. No somatic mutation was found by sequencing the 11 exons of the PRKAR2B gene. Some polymorphisms of the PRKAR 2B gene were found without any consequence at the protein level. They were also present on germline DNA. Five intronic polymorphisms were found, the most frequent (4/5 ACA-S2) being a c741+46 $\mathrm{T}>\mathrm{C}$, registered as rs3729876 in Ensembl genome database. One polymorphism in the coding region of PRKAR2B (c.1227G >A, pThr409Thr, rs257376 in Ensembl genome database) was detected in $3 / 5$ tumors. The frequency of these polymorphisms seems similar to those reported in the European population.

\section{Quantitative RT-PCR}

Since no somatic mutation of PRKAR2B gene was found in cortisol-secreting adenomas with a reduction in $\mathrm{R} 2 \mathrm{~B}$ protein, we looked for a transcriptional defect of $\mathrm{R} 2 \mathrm{~B}$ mRNA. PRKA R1A and R2B mRNA expression levels were studied by quantitative real-time PCR. A significant decrease in PRKAR1A expression was observed in the ACA-S by comparison with the ACA-NS studied $(P<0.001$; Fig. 3A). The level of R2B mRNA expression was not decreased significantly in cortisol-secreting adenomas in particular in the ACA-S2 subgroup (Fig. 3B), suggesting that the R2B protein decrease is due to a post-transcriptional alteration in ACA-S2 tumors.

\section{PKA activity}

In order to investigate the effect of R2B decrease on the cAMP/PKA signaling pathway, we performed PKA activity analysis on the available tumor samples in the ACA-S1 and ACA-S2 groups: 6/7 ACA-S1 (sample ACA \# 15 was not available) and 5/6 ACA-S2 (sample ACA \# 21 was not available) were studied for PKA activity. The basal PKA activity in the ACA-S2 group was more than threefold higher than that in the ACA-S1 group (3.37 \pm 0.31 vs $1 \pm 0.20, P<0.0001$; Fig. $4 A$ ). There is no overlap in the basal PKA activity between the two groups (Fig. 4B). However, the PKA activity stimulated by cAMP (Fig. 4C and D) was not significantly different between that of the ACA-S1 group and that of the ACAS2 group $(0.65 \pm 0.15$ vs $1 \pm 0.14, P=0.24)$.

\section{Discussion}

Various cellular and molecular alterations have been described in ACT. Some alterations such as TP53 mutations or IGF-II uniparental disomy are observed in malignant tumors, whereas others like $\beta$-catenin mutations can be observed both in ACA and in ACC (19-21). The cellular and genetic alterations that lead to an activation of the cAMP pathway are usually observed in benign unilateral or bilateral cortisol-secreting tumors (22). Alterations of membrane receptor expression are observed very frequently in macronodular adrenocortical hyperplasia, a form of bilateral benign ACT (23). The case of ectopic expression of the gastric inhibitory peptide (GIP) receptor is the best illustration of this phenomenon in patients with food-dependant Cushing's syndrome. The ectopic expression of the GIP receptor which leads to the stimulation of cAMP production can also be observed in some rare ACA (24). Germline or diffuse mosaic genetic defects as ACTHR, G $\alpha$ s, PRKAR1A, or PDE11A4 mutations are responsible for bilateral cortisol-secreting ACT (7, 9, 25). Somatic mutations of $G \alpha s$ and PRKAR1A have been observed rarely in secreting benign unilateral ACT $(8,13)$. On the other hand in ACC a decreased expression 

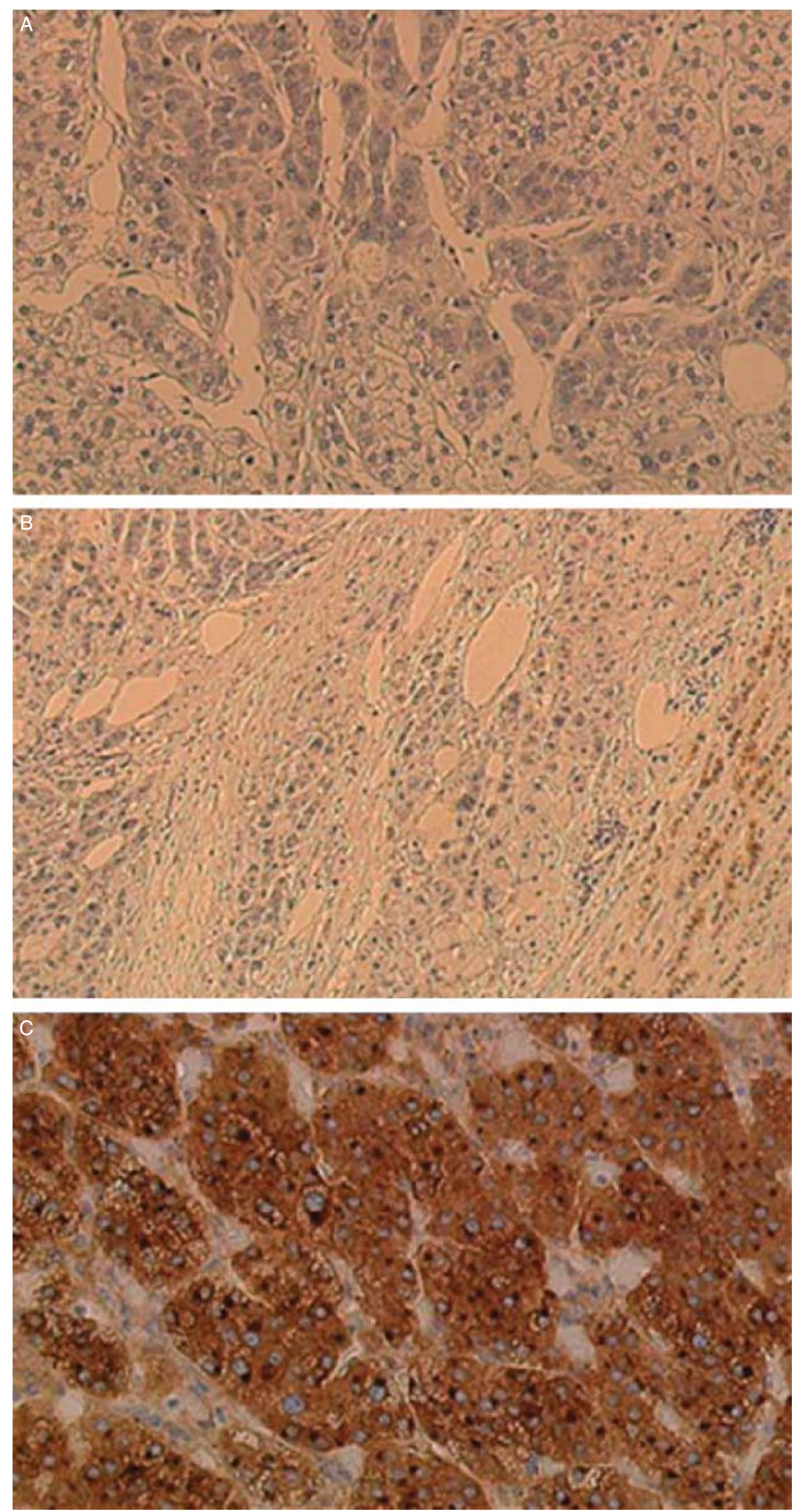

Figure 2 Immunohistochemistry of the R2B PKA subunit in adrenocortical adenomas. (A and B) An illustrative immunostaining of R2B in ACA-S2 is shown with the use of a specific R2B antibody on the tumors \# A19 (A) and \# A20 (B) from the ACA-S2 group ( $\times 200)$. There is no staining for R2B in this ACA-S in accordance with the western blot results. (C) An illustrative immunostaining of R2B in ACA-S1 is shown on tumor \# A12 ( $\times 200)$. A strong cytoplasmic immunoreactivity for R2B $(10 \%)$ is observed on this secreting adenoma, as expected from the western blot results. 


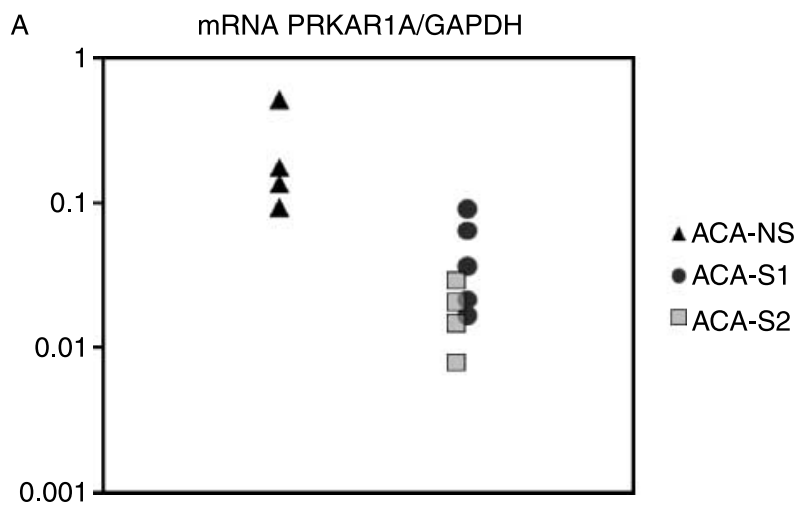

B

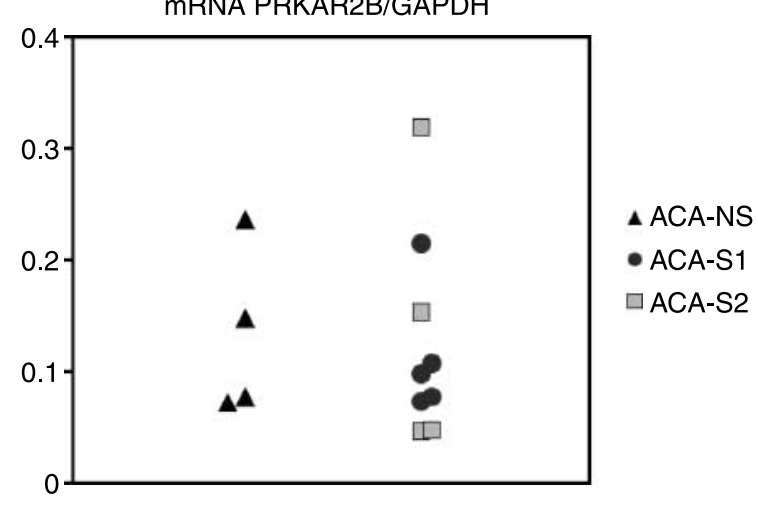

Figure 3 Quantification of PKA regulatory subunit mRNA in adrenocortical tumors. (A) The figure shows the results of PRKAR1A mRNA quantification as determined by real-time PCR. The results are expressed as copies of PRKAR1A relative to GAPDH (four ACA-NS, five ACA-S1, and four ACA-S2). The level of R1A mRNA was decreased significantly in the nine cortisol-secreting adenomas (ACA-S) studied $(P<0.001)$. (B) The figure shows the results of PRKAR2B mRNA quantification as determined by realtime PCR. The results are expressed as copies of PRKAR2B relative to GAPDH (four ACA-NS, five ACA-S1, and four ACA-S2). The level of R2B mRNA was not decreased significantly in cortisol-secreting adenomas in particular in the ACA-S2 subgroup.

of the transcription factor CREB suggests that inhibition of the cAMP pathway at the nuclear levels is involved in malignant ACT development (26-28).

The present study is in agreement with the hypothesis that alterations leading to stimulation of the cAMP pathway might be frequently involved in benign ACT, especially cortisol-secreting tumors. Several R1A abnormalities have been described in some sporadic endocrine tumors such as 17q22-24 losses in macronodular adrenal hyperplasia (29), somatic PRKAR1A mutation in thyroid cancer (18), low or absent expression of R1A protein in GH-producing adenomas (30), giving clues about endocrine tumorigenesis. Concerning adrenal tumorigenesis, in a previous study, we have observed somatic PRKAR $1 \mathrm{~A}$ mutations and R1A down-regulation in a subset of secreting ACA presenting some clinical homology with PPNAD (13). Since somatic mutations of $G \alpha s$ and
PRKAR1A are observed in a small proportion of secreting ACA $(8,13)$, we postulated that other alterations of PKA could be observed in these tumors.

Our results demonstrate in a series of ACT that the deficiency of PKA regulatory subunit 2B (PRKAR2B) is a common event in cortisol-secreting ACA, which could involve up to $50 \%$ of these adenomas. A very recent study suggests that R2B loss could be constant in ACA-S (31). However, our results suggest that the PRKAR2B status in ACA-S is more complex; two group of ACA-S can be defined according to their R2B levels. Since PRKAR1A germline mutations have been described in the $\mathrm{CNC}$, most studies focus on R1A. This finding confirms that PKA regulation might be more complex than was initially thought, and that type II PKA alterations might play a role in endocrine tumorigenesis. It is striking that the phenotype of the ACT with R2B loss is quite homogenous, since it was not observed in cancer or non-secreting tumors. Interestingly, these benign tumors with R2B loss are all small and tend to be smaller than the benign adenomas that did not exhibit R2B loss. There is no clear difference in the steroid levels between ACA-S1 and ACAS2 (urinary free cortisol levels, plasma cortisol levels, androgens levels). However, studies on a larger group of tumor might allow the detection of subtle differences. The clinical characteristics of these adenomas that were both secreting and small are similar to the phenotype of adenomas harboring a somatic PRKAR 1A mutation (13). However, one clear difference between those two groups of benign secreting tumors with PKA dysregulation is the response to exogenous glucocorticoids. The secreting adenomas with R2B protein loss (ACA-S2) do not show a 'paradoxical' response to dexamethasone, unlike the subset of secreting ACA with somatic PRKAR 1 A mutation (13). None of the patients included in the present series with an ACA-S2 presented a paradoxical response to dexamethasone (data not shown). Therefore, from the clinical point of view, subtle differences can be observed among these two groups of adenomas that are quite similar at the first look.

At the level of enzymatic activity, the ACA with R2B loss clearly have an increased basal PKA activity. The R2Bdeficient mice display a lean phenotype, nocturnal hyperactivity, and increased resting metabolic rate $(32$, 33). There is no mention about the endocrine tissues in this model. In tissue from these knockout mice the basal PKA activity is increased. In ACT with R2B loss, the stimulation of PKA activity can be explained by the preservation of the catalytic subunit. In this case, the R2B/ $\mathrm{C} \alpha$ ratio would favor an increased PKA activity. Esapa et al. also observed that an alteration of the catalytic subunit of PKA is detected neither in thyroid tumors nor in pituitary adenomas (34). The tendency for a decreased level of R2A and R1A proteins in the ACA-S2 group might also take part in this stimulation of basal PKA activity. Clearly, in these adenomas, the R2B decrease is not compensated by overexpression of the other regulatory subunits. The analysis showed a positive correlation between $\mathrm{R} 2 \mathrm{~B}$ and 
A

Basal PKA activity

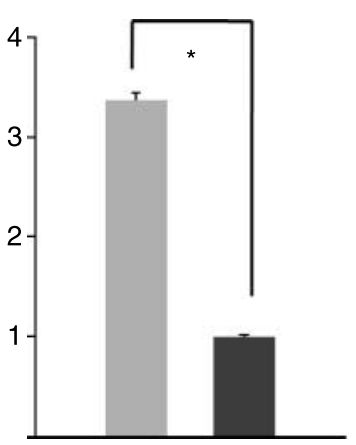

C

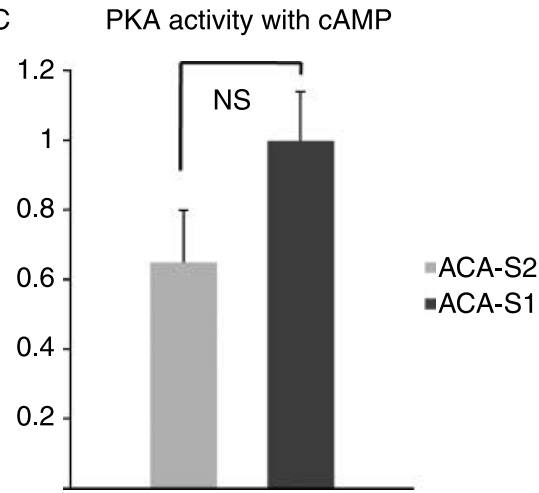

B

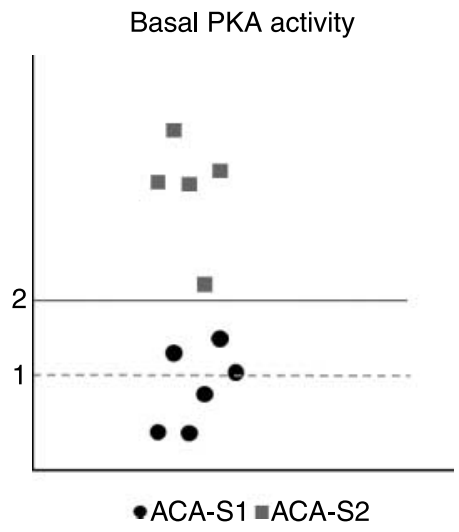

D

PKA activity with cAMP

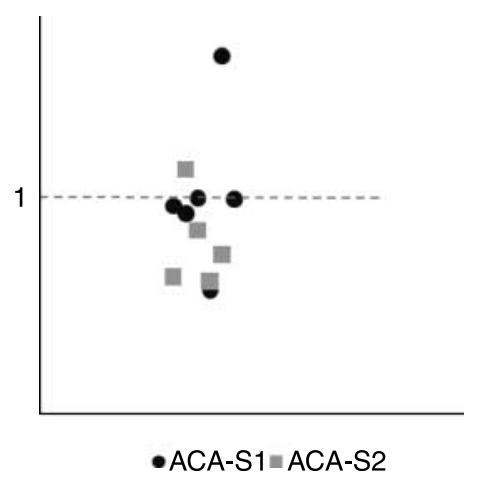

Figure 4 PKA activity in secreting adenocortical adenomas. (A and B) Basal PKA activity determined in the ACA-S1 and ACAS2 using Peptag assay. The histogram shown in $(A)$ represents the mean value of PKA activity in respectively five ACA-S2 and six ACA-S1. A dramatic increase in the basal PKA activity is observed in the ACAS2 group of secreting adenomas presenting a very low R2B protein level $\left({ }^{*} P<0.001\right)$. Individual values are given in $(B)$ and demonstrate that there is almost no overlap between the ACA-S1 and ACA-S2 groups. The cAMP-stimulated PKA activity represented as mean for each group or individual results $(C$ and $D)$ is not significantly different between the ACA-S1 and the ACA-S2 groups.
$\mathrm{R} 2 \mathrm{~A}$ proteins in adrenal adenomas; when $\mathrm{R} 2 \mathrm{~B}$ protein is decreased, R2A is also decreased but to a lesser extent. Moreover, we have not found by microarray a significant difference in the R2A mRNA levels between ACA-S2 and the other adenomas ( $\mathrm{J}$ Bertherat, unpublished observations). In other models, it has been hypothesized that mechanisms exist to coordinately regulate the intracellular levels of $\mathrm{R}$ and $\mathrm{C}$ protein such that cAMPdependent regulation is preserved. PKA R2B knockout mice showed a R1A protein compensation in white adipose tissue where R2B protein is usually highly expressed (32). This R1A compensation does not involve transcriptional or translational control; this seems to be explained by R1A protein stabilization with a longer halflife. The dramatic reduction of R2B protein in ACA-S2 also seems to be due to a post-trancriptional mechanism. It is explained neither by somatic PRKAR $2 B$ mutation nor by a down-regulation of R2B mRNA. The discrepancy between $\mathrm{R} 2 \mathrm{~B}$ mRNA and protein levels suggests the existence of a high rate of protein degradation in adrenal adenomas. This hypothesis has also been made in GH-secreting pituitary adenomas that present with R1A protein decrease but neither PRKAR1A mutation nor R1A mRNA decrease (30).

The expression of R1A is elevated in a variety of human non-endocrine cancers, including breast and colorectal cancers. This overexpression of R1A has also been associated with poor prognosis in patients with ovarian cancer (35). The stimulation of cell proliferation by silencing of PRKAR2B in the mouse adrenocortical cell line Y1 has been reported recently (31). In our study, the pattern of expression of R1A and R2B in the ACC was apparently not altered. The decrease observed in secreting ACA is clearly not present in ACC. This suggests that PKA clearly plays a different role in the development of malignant ACT than that in benign tumors (26). One could even speculate that the stimulation of PKA activity due to the decreasing level of PKA regulatory subunits in secreting adenomas might stimulate cellular differentiation in such a way that tumor growth would remain quite well-controlled.

\section{Conclusion}

The state of the various subunits of PKA varies between ACC and ACA, likely reflecting different pathogenic mechanisms. R2B protein is dramatically decreased in half of the cortisol-secreting adrenal adenomas that do not have a R1A mutation by a post-transcriptional mechanism. This inhibition of PRKAR2B in cortisolsecreting adenomas is a new mechanism of cAMP pathway 
dysregulation in adrenocortical tumorigenesis. It defines a new subtype of secreting ACA with high basal PKA activity associated with a homogenous clinical phenotype.

\section{Acknowledgements}

This work was supported by the Agence Nationale de la Recherche-GIS INSERM grant for rare diseases (ANR-06-MRAR-002) and by the Plan Hospitalier de Recherche Clinique (AOM 02068) to the COMETE network. We thank H Fierrard and M Risk-Rabin for their help in performing the PKA activity assay, Anne Audebourg, Jocelyne Daugabel, Christine Klein, and Patricia Morinière for their excellent technical assistance and the member of our laboratory (Endocrine Tumor and Signaling) for helpful discussions.

\section{References}

1 Libe R \& Bertherat J. Molecular genetics of adrenocortical tumours, from familial to sporadic diseases. European Journal of Endocrinology 2005153 477-487.

2 Lania A, Mantovani G \& Spada A. G protein mutations in endocrine diseases. European Journal of Endocrinology 2001145 543-559.

3 Rosenberg D, Groussin L, Bertagna X \& Bertherat J. cAMP pathway alterations from the cell surface to the nucleus in adrenocortical tumors. Endocrine Research 200228 765-775.

4 Beuschlein F, Fassnacht M, Klink A, Allolio B \& Reincke M. ACTHreceptor expression, regulation and role in adrenocortial tumor formation. European Journal of Endocrinology 2001144 199-206.

5 Groussin L, Jullian E, Perlemoine K, Louvel A, Leheup B, Luton JP, Bertagna X \& Bertherat J. Mutations of the PRKAR1A gene in Cushing's syndrome due to sporadic primary pigmented nodular adrenocortical disease. Journal of Clinical Endocrinology and Metabolism 200287 4324-4329.

6 Groussin L, Horvath A, Jullian E, Boikos S, Rene-Corail F, Lefebvre H, Cephise-Velayoudom FL, Vantyghem MC, Chanson P, Conte-Devolx B, Lucas M, Gentil A, Malchoff CD, Tissier F, Carney JA, Bertagna X, Stratakis CA \& Bertherat J. A PRKAR1A mutation associated with primary pigmented nodular adrenocortical disease in 12 kindreds. Journal of Clinical Endocrinology and Metabolism 200691 1943-1949.

7 Swords FM, Baig A, Malchoff DM, Malchoff CD, Thorner MO, King PJ, Hunyady L \& Clark AJ. Impaired desensitization of a mutant adrenocorticotropin receptor associated with apparent constitutive activity. Molecular Endocrinology $2002 \mathbf{1 6}$ 2746-2753.

8 Libe R, Mantovani G, Bondioni S, Lania AG, Pedroni C, BeckPeccoz P \& Spada A. Mutational analysis of PRKAR1A and Gs $\alpha$ in sporadic adrenocortical tumors. Experimental and Clinical Endocrinology and Diabetes 2005113 248-251.

9 Horvath A, Boikos S, Giatzakis C, Robinson-White A, Groussin L, Griffin KJ, Stein E, Levine E, Delimpasi G, Hsiao HP, Keil M, Heyerdahl S, Matyakhina L, Libe R, Fratticci A, Kirschner LS, Cramer K, Gaillard RC, Bertagna X, Carney JA, Bertherat J, Bossis I \& Stratakis CA. A genome-wide scan identifies mutations in the gene encoding phosphodiesterase 11A4 (PDE11A) in individuals with adrenocortical hyperplasia. Nature Genetics $2006 \mathbf{3 8}$ 794-800

10 Casey M, Vaughan CJ, He J, Hatcher CJ, Winter JM, Weremowicz S, Montgomery K, Kucherlapati R, Morton CC \& Basson CT.
Mutations in the protein kinase A R1alpha regulatory subunit cause familial cardiac myxomas and Carney complex. Journal of Clinical Investigation $2000 \mathbf{1 0 6}$ R31-R38.

11 Kirschner LS, Sandrini F, Monbo J, Lin JP, Carney JA \& Stratakis CA. Genetic heterogeneity and spectrum of mutations of the PRKAR1A gene in patients with the carney complex. Human Molecular Genetics 20009 3037-3046.

12 Stratakis CA, Kirschner LS \& Carney JA. Clinical and molecular features of the Carney complex: diagnostic criteria and recommendations for patient evaluation. Journal of Clinical Endocrinology and Metabolism 200186 4041-4046.

13 Bertherat J, Groussin L, Sandrini F, Matyakhina L, Bei T, Stergiopoulos S, Papageorgiou T, Bourdeau I, Kirschner LS, Vincent-Dejean C, Perlemoine K, Gicquel C, Bertagna X \& Stratakis CA. Molecular and functional analysis of PRKAR1A and its locus (17q22-24) in sporadic adrenocortical tumors: 17q losses, somatic mutations, and protein kinase A expression and activity. Cancer Research 200363 5308-5319.

14 Corbin JD, Keely SL \& Park CR. The distribution and dissociation of cyclic adenosine $3^{\prime}: 5^{\prime}$-monophosphate-dependent protein kinases in adipose, cardiac, and other tissues. Journal of Biological Chemistry $1975250218-225$.

15 Bossis I \& Stratakis CA. Minireview: PRKAR1A: normal and abnormal functions. Endocrinology 2004145 5452-5458.

16 Skalhegg BS \& Tasken K. Specificity in the cAMP/PKA signaling pathway. Differential expression, regulation, and subcellular localization of subunits of PKA. Frontiers in Bioscience 20005 D678-D693.

17 Cummings DE, Brandon EP, Planas JV, Motamed K, Idzerda RL \& McKnight GS. Genetically lean mice result from targeted disruption of the RII beta subunit of protein kinase A. Nature $1996382622-626$.

18 Sandrini F, Matyakhina L, Sarlis NJ, Kirschner LS, Farmakidis C, Gimm O \& Stratakis CA. Regulatory subunit type I-alpha of protein kinase A (PRKAR1A): a tumor-suppressor gene for sporadic thyroid cancer. Genes, Chromosomes and Cancer 200235 182-192.

19 Libe R, Fratticci A \& Bertherat J. Adrenocortical cancer: pathophysiology and clinical management. Endocrine-Related Cancer 200714 13-28.

20 Libe R, Groussin L, Tissier F, Elie C, Rene-Corail F, Fratticci A, Jullian E, Beck-Peccoz P, Bertagna X, Gicquel C \& Bertherat J. Somatic TP53 mutations are relatively rare among adrenocortical cancers with the frequent $17 \mathrm{p} 13$ loss of heterozygosity. Clinical Cancer Research 200713 844-850.

21 Tissier F, Cavard C, Groussin L, Perlemoine K, Fumey G, Hagnere AM, Rene-Corail F, Jullian E, Gicquel C, Bertagna X, Vacher-Lavenu MC, Perret C \& Bertherat J. Mutations of betacatenin in adrenocortical tumors: activation of the Wnt signaling pathway is a frequent event in both benign and malignant adrenocortical tumors. Cancer Research $2005657622-7627$.

22 Bertherat J, Groussin L \& Bertagna X. Mechanisms of disease: adrenocortical tumors - molecular advances and clinical perspectives. Nature Clinical Practice. Endocrinology and Metabolism $20062632-641$.

23 Lacroix A, Ndiaye N, Tremblay J \& Hamet P. Ectopic and abnormal hormone receptors in adrenal Cushing's syndrome. Endocrine Reviews 200122 75-110.

24 Groussin L, Perlemoine K, Contesse V, Lefebvre H, Tabarin A, Thieblot P, Schlienger JL, Luton JP, Bertagna X \& Bertherat J. The ectopic expression of the gastric inhibitory polypeptide receptor is frequent in adrenocorticotropin-independent bilateral macronodular adrenal hyperplasia, but rare in unilateral tumors. Journal of Clinical Endocrinology and Metabolism 200287 1980-1985.

25 Groussin L, Kirschner LS, Vincent-Dejean C, Perlemoine K, Jullian E, Delemer B, Zacharieva S, Pignatelli D, Carney JA, Luton JP, Bertagna X, Stratakis CA \& Bertherat J. Molecular analysis of the cyclic AMP-dependent protein kinase A (PKA) regulatory subunit 1A (PRKAR1A) gene in patients with Carney complex and primary pigmented nodular adrenocortical disease (PPNAD) reveals novel 
mutations and clues for pathophysiology: augmented PKA signaling is associated with adrenal tumorigenesis in PPNAD. American Journal of Human Genetics 200271 1433-1442.

26 Rosenberg D, Groussin L, Jullian E, Perlemoine K, Bertagna X \& Bertherat J. Role of the PKA-regulated transcription factor CREB in development and tumorigenesis of endocrine tissues. Annals of the New York Academy of Sciences 2002968 65-74.

27 Peri A, Luciani P, Conforti B, Baglioni-Peri S, Cioppi F, Crescioli C, Ferruzzi P, Gelmini S, Arnaldi G, Nesi G, Serio M, Mantero F \& Mannelli M. Variable expression of the transcription factors cAMP response element- binding protein and inducible cAMP early repressor in the normal adrenal cortex and in adrenocortical adenomas and carcinomas. Journal of Clinical Endocrinology and Metabolism 2001 86 5443-5449.

28 Rosenberg D, Groussin L, Jullian E, Perlemoine K, Medjane S, Louvel A, Bertagna X \& Bertherat J. Transcription factor $3^{\prime}, 5^{\prime}$ cyclic adenosine $5^{\prime}$-monophosphate-responsive element-binding protein (CREB) is decreased during human adrenal cortex tumorigenesis and fetal development. Journal of Clinical Endocrinology and Metabolism $2003 \mathbf{8 8} 3958-3965$.

29 Bourdeau I, Matyakhina L, Stergiopoulos SG, Sandrini F, Boikos S \& Stratakis CA. 17q22-24 chromosomal losses and alterations of protein kinase a subunit expression and activity in adrenocorticotropin-independent macronodular adrenal hyperplasia. Journal of Clinical Endocrinology and Metabolism 200691 3626-3632.

30 Lania AG, Mantovani G, Ferrero S, Pellegrini C, Bondioni S, Peverelli E, Braidotti P, Locatelli M, Zavanone ML, Ferrante E, Bosari S, Beck-Peccoz P \& Spada A. Proliferation of transformed somatotroph cells related to low or absent expression of protein kinase a regulatory subunit 1A protein. Cancer Research 200464 9193-9198.
31 Mantovani G, Lania AG, Bondioni S, Peverelli E, Pedroni C, Ferrero S, Pellegrini C, Vicentini L, Arnaldi G, Bosari S, Beck-Peccoz P \& Spada A. Different expression of protein kinase A (PKA) regulatory subunits in cortisol-secreting adrenocortical tumors: relationship with cell proliferation. Experimental Cell Research 2008314 123-130.

32 Amieux PS, Cummings DE, Motamed K, Brandon EP, Wailes LA, Le K, Idzerda RL \& McKnight GS. Compensatory regulation of RIalpha protein levels in protein kinase A mutant mice. Journal of Biological Chemistry 1997272 3993-3998.

33 Planas JV, Cummings DE, Idzerda RL \& McKnight GS. Mutation of the RIIbeta subunit of protein kinase A differentially affects lipolysis but not gene induction in white adipose tissue. Journal of Biological Chemistry $199927436281-36287$.

34 Esapa CT \& Harris PE. Mutation analysis of protein kinase A catalytic subunit in thyroid adenomas and pituitary tumours. European Journal of Endocrinology 1999141 409-412.

35 McDaid HM, Cairns MT, Atkinson RJ, McAleer S, Harkin DP, Gilmore P \& Johnston PG. Increased expression of the RIalpha subunit of the cAMP-dependent protein kinase A is associated with advanced stage ovarian cancer. British Journal of Cancer 1999 79 933-939.

Received 24 January 2008

Accepted 21 February 2008 